\title{
Does diabetes prevention translate into reduced long-term vascular complications of diabetes?
}

\author{
David M. Nathan ${ }^{1}$ • Peter H. Bennett ${ }^{2}$ • Jill P. Crandall ${ }^{3}$. Sharon L. Edelstein ${ }^{4}$ • Ronald B. Goldberg ${ }^{5} \cdot$ Steven E. Kahn $^{6}$. \\ William C. Knowler ${ }^{2} \cdot$ Kieren J. Mather $^{7}$. Sunder Mudaliar ${ }^{8} \cdot$ Trevor J. Orchard $^{9} \cdot$ Marinella Temprosa $^{4}$. \\ Neil H. White ${ }^{10}$ and the DPP Research Group ${ }^{4}$
}

Received: 21 March 2019 / Accepted: 14 May 2019 / Published online: 4 July 2019

(C) Springer-Verlag GmbH Germany, part of Springer Nature 2019

\begin{abstract}
The global epidemic of type 2 diabetes has prompted numerous studies and public health efforts to reduce its development. A variety of interventions, including lifestyle modifications and pharmacological agents directed at ameliorating the major risk factors for type 2 diabetes, are of proven efficacy in reducing the development of type 2 diabetes in people with impaired glucose tolerance. While prevention of the hyperglycaemia characteristic of diabetes is arguably an important, clinically relevant outcome, a more compelling outcome with greater clinical significance is the prevention or reduction of the relatively diabetesspecific microvascular and less-specific cardiovascular disease (CVD) complications associated with diabetes. These complications cause the majority of morbidity and excess mortality associated with diabetes. Any reduction in diabetes should, logically, also reduce the occurrence of its long-term complications; however, most diabetes prevention trials have not been of sufficient duration to allow such an evaluation. The limited long-term data, largely from the Da Qing Diabetes Prevention Study (DQDPS) and the Diabetes Prevention Program (DPP) and their respective follow-up studies (DQDPOS and DPPOS), suggest a reduction in microvascular complications and amelioration of CVD risk factors. Only the DQDPOS and Study to Prevent Non-InsulinDependent Diabetes Mellitus (STOP-NIDDM) studies have shown a reduction in CVD events and only DQDPOS has demonstrated a decrease in CVD and overall mortality. While these limited data are promising, whether diabetes prevention directly reduces complication-related morbidity and mortality remains unclear. Longer follow-up of prevention studies is needed to supplement the limited current clinical trial data, to help differentiate the effects of diabetes prevention itself from the means used to reduce diabetes development and to understand the balance among benefits, risks and costs of prevention.
\end{abstract}

Keywords Cardiovasculardisease · Cardiovascular disease risk factors · Diabetes prevention · Long-term diabetes complications · Microvascular disease $\cdot$ Review

A complete list of DPP/DPPOS centres, investigators and staff can be found in the electronic supplementary material (ESM).

Electronic supplementary material The online version of this article (https://doi.org/10.1007/s00125-019-4928-8) contains peer-reviewed but unedited supplementary material, including a slide of the figure for download, which is available to authorised users.

David M. Nathan

dppmail@bsc.gwu.edu; dnathan@mgh.harvard.edu

1 Massachusetts General Hospital Diabetes Center and Harvard Medical School, Boston, MA, USA

2 National Institute of Diabetes and Digestive and Kidney Diseases, Phoenix, AZ, USA

3 Albert Einstein College of Medicine, Bronx, NY, USA

4 DPP/DPPOS Coordinating Center, Biostatistics Center, The George Washington University, 6110 Executive Blvd, Rockville, MD, USA
5 University of Miami School of Medicine, Miami, FL, USA

6 VA Puget Sound Health Center and University of Washington School of Medicine, Seattle, WA, USA

7 Indiana University School of Medicine, Indianapolis, IN, USA

8 UC San Diego School of Medicine, San Diego, CA, USA

9 University of Pittsburgh Graduate School of Public Health, Pittsburgh, PA, USA

10 Washington University School of Medicine, St Louis, MO, USA 


$\begin{array}{ll}\text { Abbreviations } & \\ \text { ACE } & \text { Acarbose Cardiovascular Evaluation } \\ \text { ACEi } & \text { Angiotensin-converting enzyme inhibitor } \\ \text { ACR } & \text { Albumin/creatinine ratio } \\ \text { ACT NOW } & \text { Actos Now for Prevention of Diabetes } \\ \text { BMI } & \text { Body mass index }\left(\mathrm{kg} / \mathrm{m}^{2}\right) \\ \text { CAC } & \text { Coronary artery calcification } \\ \text { CIMT } & \text { Carotid intima-medial thickness } \\ \text { CVD } & \text { Cardiovascular disease } \\ \text { DPP } & \text { Diabetes Prevention Program } \\ \text { DPPOS } & \text { Diabetes Prevention Program } \\ & \text { Outcomes Study } \\ \text { DQDPOS } & \text { Da Qing Diabetes Prevention } \\ & \text { Outcome Study } \\ \text { DQDPS } & \text { Da Qing Diabetes Prevention Study } \\ \text { DREAM } & \text { Diabetes Reduction Assessment } \\ & \text { with Ramipril and } \\ & \text { Rosiglitazone Medication } \\ \text { FDPS } & \text { Finnish Diabetes Prevention Study } \\ \text { IFG } & \text { Impaired fasting glucose } \\ \text { IGT } & \text { Impaired glucose tolerance } \\ \text { ORIGIN } & \text { Outcome Reduction with an Initial } \\ \text { STOP-NIDDM } & \text { Glargine Intervention } \\ & \text { Study to Prevent Non-Insulin- } \\ & \text { Dependent Diabetes Mellitus }\end{array}$

\section{Introduction}

The association between diabetes and the increased risk for long-term microvascular complications is definitional. Specifically, the glycaemic levels selected for the diagnosis of diabetes are predicated on the levels associated with the risk of developing retinopathy $[1,2]$. Logically, therefore, prevention of diabetes should also prevent (or at least reduce) long-term diabetes-specific microvascular complications, including diabetic retinopathy, neuropathy and nephropathy: less diabetes, fewer diabetes complications.

Surprisingly, despite this ineluctable reasoning, the anticipated relationship between diabetes prevention and reduction in long-term complications has not been definitively proved. Since cardiovascular disease (CVD) is multifactorial and not diabetes-specific, prevention of diabetes might attenuate the risk for CVD or reduce its risk factors and need for antihypertensive or lipid-lowering medications. However, diabetes prevention would not be expected to have as strong an effect on reducing CVD as on microvascular complications where hyperglycaemia plays a more prominent role.

Amelioration of the long-term complications that cause most of the morbidity, mortality, suffering and cost associated with diabetes $[3,4]$ is central to defining successful prevention. We review the results of major diabetes prevention studies to assess the role of diabetes prevention on the development and progression of long-term diabetes-associated complications. Several studies that did not include diabetes prevention as the primary outcome, but which are informative, have been included.

\section{Why diabetes prevention studies that report effects on long-term complications are limited in number and difficult to interpret}

Numerous clinical trials to prevent diabetes have been performed during the past 40 years [reviewed in 5, 6]; however, only nine of them have reported the association of diabetes prevention with microvascular or CVD complications or their risk factors [7-36]. The reasons for the limited availability of data on diabetic complications from these diabetes prevention studies include the following: (1) most prevention trials have been insufficient in size and/or duration to provide data regarding the long-term complications of diabetes and (2) many prevention trials were designed to evaluate metabolic outcomes but not microvascular or cardiovascular outcomes. Details of the nine major diabetes prevention studies reporting vascular outcomes, including their study cohorts, durations and reductions in the cumulative incidence of diabetes, are summarised in Table 1. Some studies undertook long-term follow-up to ascertain vascular outcomes; generic challenges to these studies include the loss to follow-up over time that limits the confidence of findings. Moreover, once participants develop diabetes in the trials, they receive multifactorial treatment for their diabetes, which may reduce the incidence of complications. These interventions diminish the ability to detect differences that might otherwise have been attributable to 'prevention'. Finally, even the largest and longest duration prevention study reporting $\mathrm{HbA}_{1 \mathrm{c}}$ over time, the Diabetes Prevention Program (DPP) and its long-term follow-up Diabetes Prevention Program Outcomes Study (DPPOS), demonstrated only a small separation in glycaemic levels between those who developed diabetes and those who did not, with even smaller treatment-group differences. These small differences in glycaemic levels make it more difficult (perhaps impossible) to determine differences in glucose-dependent complications.

Clinical trials to prevent diabetes, conducted mainly in people with impaired glucose tolerance (IGT; see Table 1), have used a variety of interventions and it is possible that effects specific to these interventions may have confounded the assessment of the development of long-term complications by being independent of diabetes prevention or reduction in hyperglycaemia. For example, several prevention studies have used angiotensin-converting enzyme inhibitors (ACEi) or angiotensin II receptor blockers (ARBs) [23, 27]. These classes of BP-lowering medications have glucose-independent salutary effects on CVD, CVD risk factors and some 
Table 1 Description of major diabetes prevention studies reporting long-term complications

\begin{tabular}{|c|c|c|c|c|c|c|c|}
\hline Study & $\begin{array}{l}\text { Total number } \\
\text { of participants }\end{array}$ & Cohort & Duration $^{\mathrm{a}}$ & $\begin{array}{l}\text { Post-trial } \\
\text { follow- } \\
\text { up }^{\text {b }}\end{array}$ & Intervention & $\operatorname{HR}(95 \% \mathrm{CI})^{\mathrm{c}}$ & $\begin{array}{l}\mathrm{HbA}_{1 \mathrm{c}} \text { at study end }{ }^{\mathrm{d}} \text {, } \\
\text { active vs control (\%) } \\
(\mathrm{mmol} / \mathrm{mol})\end{array}$ \\
\hline DQDPS [7] & 577 & IGT & 6 & & Lifestyle & $0.49(0.33,0.73)$ & \\
\hline DQDPOS [8] & & & & 20 & Lifestyle & $0.57(0.41,0.81)$ & NA \\
\hline DQDPOS [12] & - & - & - & 30 & Lifestyle & $0.61(0.45,0.83)$ & NA \\
\hline DPP [13] & 3234 & $\begin{array}{l}\mathrm{IGT}+\mathrm{IFG}^{\mathrm{e}}+ \\
\quad \mathrm{BMI} \geq 25\end{array}$ & 2.8 & & $\begin{array}{l}\text { Lifestyle } \\
\text { Metformin }\end{array}$ & $\begin{array}{l}0.42(0.34,0.52) \\
0.69(0.57,0.83)\end{array}$ & $\begin{array}{l}5.9 \text { vs } 6.1(41 \text { vs } 43) \\
6.0 \text { vs } 6.1(42 \text { vs } 43)\end{array}$ \\
\hline DPPOS [14] & & & & 15 & $\begin{array}{l}\text { Lifestyle } \\
\text { Metformin }\end{array}$ & $\begin{array}{l}0.73(0.65,0.83) \\
0.82(0.72,0.93)\end{array}$ & $\begin{array}{l}6.2 \text { vs } 6.3(44 \text { vs } 45) \\
6.1 \text { vs } 6.3(43 \text { vs } 45)\end{array}$ \\
\hline FDPS [34] & 522 & $\mathrm{IGT}+\mathrm{BMI} \geq 25$ & 3.9 & - & Lifestyle & $0.42(0.3,0.7)$ & NA \\
\hline NAVIGATOR $[22,23]$ & 9306 & $\begin{array}{l}\text { IGT }+ \text { CVD or } \\
\text { CVD risk factors }\end{array}$ & 5 & - & $\begin{array}{l}\text { Nateglinide } \\
\text { Valsartan }\end{array}$ & $\begin{array}{l}1.07(1.0,1.15) \\
0.86(0.8,0.92)\end{array}$ & $\begin{array}{l}6.1 \text { vs } 6.3(43 \text { vs } 45) \\
\text { NA }\end{array}$ \\
\hline ACE [26] & 6522 & $\mathrm{IGT}+\mathrm{CHD}$ & 5 & - & Acarbose & $0.82(0.71,0.94)$ & 5.88 vs $5.94(41$ vs 41$)$ \\
\hline ACT NOW [30] & 602 & $\begin{array}{c}\mathrm{IGT}+\mathrm{IFG}+ \\
\mathrm{BMI} \geq 25\end{array}$ & 2.3 & - & Pioglitazone & $0.28(0.16,0.49)$ & 5.50 vs 5.70 (37 vs 39$)$ \\
\hline STOP-NIDDM [24] & 1429 & $\begin{array}{c}\mathrm{IGT}+\mathrm{IFG}+ \\
\mathrm{BMI} \geq 25\end{array}$ & 3.3 & - & Acarbose & $0.75(0.63,0.90)$ & NA \\
\hline ORIGIN [32] & 1456 & $\begin{array}{l}\text { CVD + IGT } \\
\text { or IFG }\end{array}$ & 6.2 & - & Glargine & $0.72(0.58,0.90)$ & 6.3 vs 6.5 (45 vs 48$)$ \\
\hline DREAM $[27,28]$ & 5269 & IGT and or IFG & 3 & - & $\begin{array}{l}\text { Rosiglitazone } \\
\text { Ramipril }\end{array}$ & $\begin{array}{l}0.38(0.33,0.44) \\
0.91(0.80,1.03)\end{array}$ & NA \\
\hline
\end{tabular}

${ }^{\text {a }}$ Duration of original controlled clinical trial in years

${ }^{\mathrm{b}}$ Total follow-up from randomisation in years

${ }^{\mathrm{c}} \mathrm{HR}$ of active intervention vs control for annual incidence (all studies except ORIGIN, which reports OR) for diabetes development. All studies represent reduction in annual incidence $(95 \% \mathrm{CI})$ except DREAM and NAVIGATOR, which analysed differences in prevalence at study end. All reductions in diabetes incidence significant $(p<0.05)$ compared with control group except for nateglinide in NAVIGATOR study and ramipril in DREAM

${ }^{\mathrm{d}} \mathrm{HbA}_{1 \mathrm{c}}$ levels between active and control groups at study end, except in DPPOS where $\mathrm{HbA}_{1 \mathrm{c}}$ is the mean over the entire 15 years of follow-up, in ACE where the $\mathrm{HbA}_{1 \mathrm{c}}$ difference is at 1 year and in ORIGIN where $\mathrm{HbA}_{1 \mathrm{c}}$ is at 6 years

${ }^{\mathrm{e}} \mathrm{IFG}$ in DPP was a fasting plasma glucose of $5.3-6.9 \mathrm{mmol} / \mathrm{l}(95-125 \mathrm{mg} / \mathrm{dl})$

NA, not available; CHD, coronary heart disease

microvascular complications and thus might reduce complications independent of the prevention of diabetes.

\section{Microvascular complications}

Various microvascular complications have been measured, some more objectively than others, and we have indicated which complications have been measured in each of the nine prevention trials of interest. The two largest prevention studies that have performed long-term follow-up to examine microvascular complications are the Da Qing Diabetes Prevention Study (DQDPS) with its long-term follow-up (Da Qing Diabetes Prevention Outcome Study [DQDPOS]) [7-12] and the DPP and its DPPOS extension [13-21]. Both of these trials utilised lifestyle modifications directed at ameliorating obesity and sedentary lifestyle, the major risk factors for type 2 diabetes. DPP/DPPOS also used metformin in a separate treatment arm. Other studies with fewer participants or shorter duration that have examined the role of medications in diabetes prevention have also reported microvascular results
[26-29]. Finally, some studies not directly focusing on diabetes prevention have reported diabetes prevention and diabetes vascular complications as secondary outcomes [32, 33].

Da Qing Diabetes Prevention Study The DQDPS, which began in 1986, and its outcome study DQDPOS, reported microvascular outcomes (retinopathy, nephropathy and neuropathy) after 20 years of follow-up in 94\% of the original 6 year diabetes prevention trial cohort [9]. Since reduction in diabetes incidence was not different among the three original clinicrandomised lifestyle intervention groups (diet, exercise, and diet + exercise) at the end of the trial, the investigators combined the three active intervention groups into a single group for follow-up analysis of complications. As interim examinations for complications were not performed during follow-up, the outcomes reported were limited to those that could be reliably identified and assessed retrospectively from medical history and records or from history and clinical examination of living participants at the 20 year time point. Severe retinopathy was defined as vision loss, proliferative retinopathy or photocoagulation therapy identified by record review or by 
slit-lamp biomicroscopy or fundus photographs in the examined survivors. Severe nephropathy was defined as kidney failure requiring renal replacement therapy, death from renal disease or an albumin/creatinine ratio (ACR) $\geq 300 \mathrm{mg} / \mathrm{g}$ (34 $\mathrm{mg} / \mathrm{mmol}$ ). Neuropathy was defined as a history of lower-extremity ulceration, gangrene or amputation or loss of light touch sensation with a $10 \mathrm{~g}$ monofilament. The cumulative incidence and prevalence of these conditions at the 20 and 30 year evaluations were compared between the combined intervention groups and the control group [9, 12].

The 20 year analyses revealed that the incidence rate of severe retinopathy was reduced by $47 \%$ but nonproliferative retinopathy was not significantly different between the active intervention and control groups. Severe nephropathy was infrequent and not significantly different between the two groups (2.0\% vs $2.1 \%)$. Similarly, among survivors the proportion displaying an ACR $\geq 300 \mathrm{mg} / \mathrm{g}$ ( $34 \mathrm{mg} /$ $\mathrm{mmol})$ and 30-299 mg/g (3.4-34 mg/mmol) did not differ significantly between the active treatment and control groups ( $4.0 \%$ vs $4.6 \%$ and $36.6 \%$ vs $40.5 \%$, respectively), nor was prevalence of neuropathy different $(8.6 \%$ vs $9.1 \%)$. Comparing participants who developed diabetes with those who did not, $41.6 \%$ vs $14.3 \%$ developed non-proliferative retinopathy $(p<0.0001)$ independent of their original treatment assignments; only participants who developed diabetes in either treatment group had developed renal failure. The secondary epidemiological analyses of prevention trial results are by nature less compelling than the primary intention-totreat analyses; however, they do provide insight into the consequences of developing diabetes in comparison with blood glucose levels remaining at sub-diabetes levels.

The 30 year DQDPS followed $94 \%$ of the original cohort and demonstrated a $35 \%$ lower risk $(p=0.025)$ of composite microvascular outcomes (cumulative incidence of $25.1 \%$ [95\% CI 20.2,30.1] in the combined intervention group vs $34.0 \%$ [95\% CI 24.5, 43.8] in the control group) [12]. The cumulative incidence of retinopathy was $40 \%$ lower $(p=0.032)$ in the intervention vs control groups; although nominally lower in the active intervention groups, incidences of nephropathy and neuropathy did not significantly differ from those in control.

\section{Diabetes Prevention Program and Outcome Study The DPP} was a randomised controlled clinical trial conducted in 27 centres across the USA during 1996-2001 [13]. It compared intensive lifestyle intervention, double-blinded metformin (850 mg twice daily) and matching placebo. The DPPOS followed $88 \%$ of the original DPP cohort, with unblinded metformin continued in the original DPP-assigned metformin group and reduced-intensity lifestyle intervention offered to all three of the original intervention groups [14]. Long-term outcomes were measured objectively using methods similar to those in DQDPOS. To improve power, the primary microvascular complications outcome was a composite including retinopathy (Early Treatment Diabetic Retinopathy Study [ETDRS] severity score $\geq 20$ in either eye by fundus photography), nephropathy (annual urinary ACR $\geq 30 \mathrm{mg} / \mathrm{g}[3.4 \mathrm{mg}$ / mmol] or eGFR $\left.<45 \mathrm{ml} \mathrm{min}^{-1}[1.73 \mathrm{~m}]^{-2}\right)$ or neuropathy $(<8$ of 10 monofilament light touches recognised). The average prevalence of each of these outcomes after a mean 15 years of follow-up was not significantly different among the three intervention groups (12.4\% of the placebo group, $13.0 \%$ of metformin group and $11.3 \%$ of intensive lifestyle intervention group). The separation in $\mathrm{HbA}_{1 \mathrm{c}}$ levels among treatment groups was small (Table 1, Fig. 1). In a pre-specified subgroup analysis by sex, women in DPPOS, representing $68 \%$ of the entire cohort, showed a significant reduction in prevalence of the aggregate microvascular outcome with lifestyle intervention compared with placebo and metformin $(8.7 \%$ vs $11.0 \%$ and $11.2 \%$, respectively), with a $21 \%$ and $22 \%$ relative risk reduction $(p<0.05)$, respectively. In addition, a $28 \%$ significant reduction in prevalence of complications was observed in individuals that did not develop diabetes vs those who did, independent of treatment assignment. The separation in $\mathrm{HbA}_{1 \mathrm{c}}$ levels between the diabetic and non-diabetic subcohorts was $0.8 \%(8.7 \mathrm{mmol} / \mathrm{mol})$ at year 15 [14].

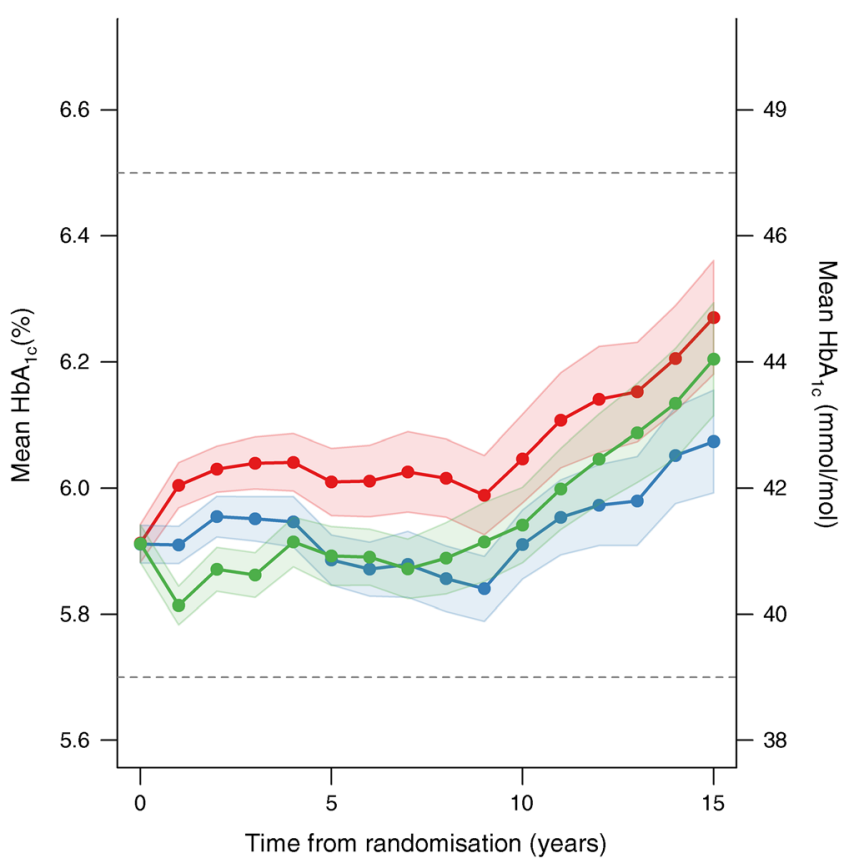

Fig. $1 \mathrm{HbA}_{1 \mathrm{c}}$ levels and $95 \%$ confidence bands, measured annually over time in DPP/DPPOS in all participants, based on original intention-to-treat assignments (red, placebo; green, intensive lifestyle intervention; blue, metformin). The coloured area surrounding each line represents the $95 \%$ CI. The differences in the mean $\mathrm{HbA}_{1 \mathrm{c}}$ over time for intensive lifestyle intervention vs placebo, and metformin vs placebo, were significant $(p<0.001)$. The dashed lines reflect the $\mathrm{HbA}_{1 \mathrm{c}}$ levels currently used by the American Diabetes Association to define 'prediabetes' (5.7-6.4\% [39$46 \mathrm{mmol} / \mathrm{mol}])$ and diabetes ( $\geq 6.5 \%[48 \mathrm{mmol} / \mathrm{mol}])$. Values in $\mathrm{mmol} / \mathrm{mol}$ on the right-hand $y$-axis are converted from the $\%$ values on the left and rounded up or down. This figure is available as a downloadable slide 
Outcome Reduction with an Initial Glargine Intervention Study Other studies have examined the effects of medications on diabetes incidence and reported vascular complications and risk factors (Table 1). For example, the Outcome Reduction with an Initial Glargine Intervention (ORIGIN) study of glargine therapy in individuals with dysglycaemia included almost 1500 participants (out of more than 12,000) who had IGT at baseline [32]. Analyses of the entire cohort over 6.2 years examined the development of advanced microvascular complications (kidney disease defined as severe nephropathy with renal failure or doubling of serum creatinine or change in albuminuria from normoalbuminuria to microalbuminuria or microalbuminuria to "clinical proteinuria'; severe retinopathy defined as a history of photocoagulation or vitrectomy) in subcohorts with baseline $\mathrm{HbA}_{1 \mathrm{c}}$ $<6.4 \%(46 \mathrm{mmol} / \mathrm{mol})$ and $\geq 6.4 \%$ [33]. In the subcohort with baseline $\mathrm{HbA}_{1 \mathrm{c}}<6.4 \%$ ( $46 \mathrm{mmol} / \mathrm{mol}$ ), there was no significant difference between the glargine intervention and placebo (HR 1.07 [95\% CI 0.95, 1.20]) in preventing these advanced complications. In the subgroup with baseline $\mathrm{HbA}_{1 \mathrm{c}} \geq 6.4 \%$ $(46 \mathrm{mmol} / \mathrm{mol})$, the glargine intervention resulted in a significant reduction in these advanced complications (HR 0.90 [95\% CI 0.891, 0.99]). Of note, the separation in $\mathrm{HbA}_{1 \mathrm{c}}$ achieved with glargine vs placebo in the higher-baseline $\mathrm{HbA}_{1 \mathrm{c}}$ group was $0.33 \%$ (3.6 mmol/mol) compared with $0.22 \%(2.4 \mathrm{mmol} / \mathrm{mol})$ in the lower baseline group. The development of complications overall was strongly related to $\mathrm{HbA}_{1 \mathrm{c}}$ level.

Acarbose Cardiovascular Evaluation trial In the large prospective randomised Acarbose Cardiovascular Evaluation (ACE) trial [26] comparing acarbose vs placebo in a study of secondary CVD prevention in IGT, severe nephropathy (defined as clinical renal failure, doubling of serum creatinine or a $50 \%$ reduction in eGFR) was reduced by a non-significant $19 \%$ $(1.3 \%$ vs $1.5 \%)$ in the acarbose group compared with placebo. Diabetes development was reduced by $18 \%$ with acarbose ( $p=0.005)$ but $\mathrm{HbA}_{1 \mathrm{c}}$ was separated by only $0.07 \%$ (5.88 vs $5.94 \%$ [ 40.8 vs $41.4 \mathrm{mmol} / \mathrm{mol}]$ ).

The Diabetes Reduction Assessment with Ramipril and Rosiglitazone Medication trial The Diabetes Reduction Assessment with Ramipril and Rosiglitazone Medication (DREAM) trial was a $2 \times 2$ factorial study that examined the effects of the ACEi ramipril [27] and the thiazolidinedione rosiglitazone [28] on the development of diabetes in a cohort with IGT and/or impaired fasting glucose (IFG). Ramipril had no significant effect on diabetes development and is not discussed further; however, rosiglitazone substantially reduced the proportion of individuals who developed diabetes $(11.6 \%$ with rosiglitazone vs $26.0 \%$ with placebo; HR 0.38 [95\% CI $0.33,0.44])$, the reduction being similar in magnitude to that found in other prevention studies with thiazolidinediones [30].
During the 36 month study, rosiglitazone resulted in $20 \%$ reduction $(12.3 \%$ vs $15 \%, p=0.005)$ in renal outcomes (a composite of any of the following: progression from normoalbuminuria to either microalbuminuria or proteinuria or from microalbuminuria to proteinuria; a decrease in eGFR of $\geq 30 \%$ or renal insufficiency requiring dialysis or transplantation) compared with placebo [29]. The beneficial effect of rosiglitazone was largely based on a reduction in the progression of albuminuria. The percentage of individuals experiencing a decrease in eGFR by $\geq 30 \%$ was nominally but not significantly reduced by rosiglitazone (3.1\% vs $4.0 \%$; HR 0.77 [95\% CI 0.58, 1.04]). In a logistic model including medication assignment and baseline ACR and eGFR, the composite renal outcome was associated with incident diabetes (HR 1.42 [95\% CI 1.16, 1.74]) and inversely with rosiglitazone (HR 0.83 [95\% CI $0.70,0.98])$.

\section{Cardiovascular disease, atherosclerosis and CVD risk factors}

Considering the dominant role played by CVD in the excess mortality associated with diabetes, it is not surprising that diabetes prevention trials have included analyses of CVD risk factors, non-fatal CVD events, CVD mortality and other measures of atherosclerosis $[8,10-12,16-26,29-32,34-36]$ (Table 2). As with microvascular complications, the effects of diabetes prevention on CVD outcomes may be confounded by the extra-glycaemic effects of the interventions used in individual trials. Moreover, when lifestyle interventions have been effective in reducing CVD risk factors, the use of medications with proven benefit for CVD has been reduced [16], with a potential adverse effect on CVD development.

Prevention of cardiovascular events In the 20 year follow-up of DQDPS, there were no significant differences between the original groups assigned to lifestyle interventions and the control group in the rate of first CVD events or mortality, despite a $43 \%$ lower incidence of diabetes over the 20 years [8]. However, by the 23 year follow-up report, a significant reduction in the cumulative incidence of CVD mortality $(11.9 \%$ vs $19.6 \%$; HR 0.59 [95\% CI 0.36, 0.96]) and all-cause mortality ( $28.1 \%$ vs $38.4 \%$; HR 0.71 [95\% CI $0.51,0.99]$ ) was observed [10]. The 30 year follow-up of DQDPS further supported the CVD and mortality benefits of diabetes prevention, with $26 \%$ (95\% CI 8,$41 ; p=0.006)$ lower CVD events in the combined treatments groups than the control group (cumulative incidence $52.9 \%$ [ $95 \%$ CI $47.5,57.9$ ] vs $66.5 \%$ [95\% CI 57.0, 74.4]) [12]. Cardiovascular and all-cause mortality were also significantly lower in the combined treatment groups than in the control group, with cumulative incidences of $25.6 \%$ and $35.2 \%$ (33\% lower [95\% CI 60, 52], $p=0.022$ ), respectively, 
Table 2 Cardiovascular events and subclinical atherosclerosis measures in active intervention vs control groups from major diabetes prevention trials

\begin{tabular}{|c|c|c|c|c|c|}
\hline Study & Outcome $^{\mathrm{a}}$ & Average follow-up (years) & Active & Control & HR $(95 \% \mathrm{CI})$ \\
\hline \multicolumn{6}{|l|}{ CVD events } \\
\hline DQDPS/DQDPOS $[8,12]$ & MACE & & & & \\
\hline \multirow[t]{3}{*}{ Cumulative incidence, $\%$} & & 6 & $5.2(3.0,7.3)$ & $5.4(1.5,9.2)$ & $0.96(0.76,1.44)$ \\
\hline & & 20 & $40.9(36.0,45.9)$ & $44.1(35.3,53.0)$ & $0.98(0.71,1.37)$ \\
\hline & & 30 & $52.9(47.5,57.9)$ & $66.5(57.0,74.4)$ & \\
\hline \multirow[t]{3}{*}{ Incidence rate, per 1000 person-years } & & 6 & $9.0(5.0,13.0)$ & $9.0(2,16)$ & \\
\hline & & 20 & $23.0(19,27)$ & $25.0(19,32)$ & \\
\hline & & 30 & $22.2(19.2,25.6)$ & $29.5(23.4,36.7)$ & $0.74(0.59,0.92)^{*}$ \\
\hline DQDPS/DQDPOS $[8,10,12]$ & CVD mortality & & & & \\
\hline \multirow[t]{3}{*}{ Cumulative incidence, $\%$} & & 20 & $12.5(9.1,15.8)$ & $17.4(10.6,24.2)$ & $0.83(0.48,1.04)$ \\
\hline & & 23 & $11.9(8.8,15.0)^{\mathrm{c}}$ & $19.6(12.9,26.3)$ & $0.59(0.36,0.96)^{*}$ \\
\hline & & 30 & $25.6(21.1,30.4)$ & $35.2(26.4,44.2)$ & $0.67(0.48,0.94)^{*}$ \\
\hline \multirow[t]{3}{*}{ Incidence rate, per 1000 person-years } & & 20 & $6(5,8)$ & $9(5,13)$ & \\
\hline & & 23 & $6.0(4.4,7.7)$ & $10.1(6.3,14)$ & \\
\hline & & 30 & $8.7(7.0,12.7)$ & $12.6(9.0,17.1)$ & \\
\hline FDPS [34] & MACE & & & & \\
\hline Incidence rate, per 1000 person-years & & 10.2 & $22.9(17.7,29.7)$ & $22.0(16.9,28.7)$ & $1.04(0.72,1.51)$ \\
\hline STOP-NIDDM [25] & MACE & 3.3 & 2.2 & 4.7 & $0.51(0.28,0.95)^{*}$ \\
\hline ACE [26] & MACE & 5.0 & 3.3 & 3.4 & $0.98(0.86,1.11)$ \\
\hline DREAM-Rosiglitazone [29] & MACE & 3.0 & 1.3 & 0.9 & $1.43(0.84,2.44)$ \\
\hline DREAM-Ramipril [29] & MACE & 3.0 & 1.0 & 1.1 & $0.94(0.56,1.59)$ \\
\hline ORIGIN [32] & MACE & 6.2 & 2.9 & 2.9 & $1.02(0.94,1.11)$ \\
\hline NAVIGATOR-Valsartan [23] & MACE & 6.4 & 1.4 & 1.5 & $0.96(0.86,1.07)$ \\
\hline \multicolumn{6}{|l|}{ Subclinical atherosclerosis measures ${ }^{\mathrm{b}}$} \\
\hline \multirow[t]{2}{*}{ DPPOS-Met [17] } & CAC-Men & 14 & $39.5(26.7,58.4)^{*}$ & $66.9(45.3,98.8)$ & \\
\hline & CAC-Women & 14 & $4.8(3.4,7.0)$ & $4.7(3.3,6.8)$ & \\
\hline \multirow[t]{2}{*}{ DPPOS-ILS [17] } & CAC-Men & 14 & $58.3(39.4,86.4)$ & $66.9(45.3,98.8)$ & \\
\hline & CAC-Women & 14 & $5.2(6.3,7.5)$ & $4.7(3.3,6.8)$ & \\
\hline ACT NOW [31] & CIMT & 2.3 & $4.76(2.39,7.13)^{*}$ & $9.69(7.24,12.15)$ & \\
\hline DREAM (STARR-Rosi) [36] & CIMT & 3.0 & $6.3 \pm 1.1$ & $9.0 \pm 1.1$ & \\
\hline DREAM (STARR-Rami) [36] & CIMT & 3.0 & $8.3 \pm 1.1$ & $6.9 \pm 1.1$ & \\
\hline
\end{tabular}

${ }^{a} \mathrm{CVD}$ events are major cardiovascular events, the components of which differ somewhat between studies and are expressed as incidence rate per 100 person-years, unless stated otherwise. For DQDPS/DQDPOS and FDPS, cumulative incidence is expressed as \% (95\% CI) and incidence is expressed per 1000 person-years $(95 \% \mathrm{CI})$. For DREAM-Rosiglitazon and -Ramipril, data are per cent of participants with event

${ }^{\mathrm{b}} \mathrm{CAC}$ is expressed as mean (95\% CI) age-adjusted coronary artery calcium severity in Agatston units; CIMT was expressed as annual progression (95\% $\mathrm{CI})$ in $10^{-3} \mathrm{~mm}$ for ACT NOW and mean \pm SEM for DREAM

${ }^{\mathrm{c}}$ The apparent reduction in cumulative incidence between DQDPOS years 20 and 23 was owing to recapture of participants previously lost to follow-up and more complete ascertainment of cause of death

${ }^{*} p<0.05$ for difference between treatment groups

ILS, lifestyle intervention; MACE, major adverse cardiovascular events; STARR-Rami/Rosi, Study of Atherosclerosis with Ramipril and Rosiglitazone

for CVD death and $45.5 \%$ and $56.3 \%$ (26\% lower [95\% CI 11, $39], p=0.0015)$ for all-cause mortality.

The multinational Study to Prevent Non-Insulin-Dependent Diabetes Mellitus (STOP-NIDDM) trial, which reported that acarbose compared with placebo reduced the development of diabetes by $36 \%$ over 40 months [24], unexpectedly demonstrated a $49 \%$ reduction in major CVD outcomes $(2.2$ vs $4.7 \%$ cumulative incidence; HR 0.51 [95\% CI 0.28, 0.95]) including a significant reduction in myocardial infarction [25]. Acarbose therapy was also associated with a $34 \%$ relative risk reduction in the incidence of hypertension (absolute risk reduction of $5.3 \%$ ), strongly associated with the CVD outcome. The 60 month ACE study [26], conducted in China, did not confirm the beneficial effects of acarbose on CVD seen in STOPNIDDM. Despite an $18 \%$ reduction in diabetes development in the ACE study, there was no significant reduction in incidence 
of CVD (a five-point composite of cardiovascular death, nonfatal myocardial infarction, non-fatal stroke, hospital admission for unstable angina and hospital admission for heart failure) with acarbose compared with placebo (3.3 vs 3.4 per 100 -patient years; HR 0.98 [95\% CI 0.86, 1.11]) and no significant reduction in any of the individual elements of the composite [26]. Similarly, compared with the control groups, no differences in incidence of major cardiovascular events were found in the intervention groups in ORIGIN [32], in the valsartan arm of NAVIGATOR [23] or with lifestyle intervention in the 10 year follow-up of the Finnish Diabetes Prevention Study (FDPS) [37], studies in which development of diabetes was reduced by $28 \%, 14 \%$ and $58 \%$, respectively (Table 1). Furthermore, although diabetes development was reduced by $60 \%$ in the rosiglitazone arm of DREAM compared with the placebo arm [28], no significant effect was found for MACE events (1.3\% vs 0.9\%; HR 1.43 [95\% CI 0.84, 2.44]) [29] (Table 2). None of these trials were powered to test the effect of interventions on CVD outcomes. In contrast, the ongoing DPPOS is powered to detect a $30 \%$ reduction in major cardiovascular events between the metformin and placebo arms. DPPOS has not yet accumulated sufficient events to undertake the analysis.

Effects on measures of atherosclerosis Although the study of the effects of diabetes prevention on CVD outcomes may require decades of follow-up to collect enough data on CVD events, surrogate outcomes such as coronary calcification (CAC) and carotid intimal-medial thickness (CIMT) can yield valuable interim information (Table 2). In the DPPOS, CAC was measured after approximately 14 years of follow-up in 2029 individuals [17]. Intention-to-treat analysis revealed that men but not women in the metformin group had lower CAC severity and prevalence than in the placebo group. In an epidemiological analysis, $84 \%$ of men and $50 \%$ of women in the placebo group had detectable CAC, and CAC severity was greater in those who had developed diabetes compared with those who had not. CIMT was measured at baseline and 2-3 years after randomisation in subsets of several thiazolidinedione prevention trials, including Actos Now for Prevention of Diabetes (ACT NOW) [31] and the DREAM Study of Atherosclerosis with Ramipril and Rosiglitazone (STARR) [36]. Progression of CIMT was significantly decreased by pioglitazone [31] but not rosiglitazone [36], despite similar, high rates of reduction in diabetes development $(60-72 \%)$ in the studies. While the findings using CAC and CIMT as markers of subclinical atherosclerosis demonstrate favourable effects of several interventions, whether the results are a function of diabetes prevention or the specific medications, independent of diabetes prevention, is unknown.

Effects on CVD risk factors Many diabetes prevention trials, conducted mainly in people with IGT, have reported the effects of interventions directed at diabetes prevention on conventional CVD risk factors, such as BP and lipids, and novel cardiometabolic biomarkers over time. Favourable effects have been recorded for lifestyle, metformin, acarbose and thiazolidinedione interventions. During the original 3.2 year DPP, compared with placebo, lifestyle intervention was associated with significant improvements in systolic and diastolic BP, HDL-cholesterol, triacylglycerol levels and LDL particle size, as well as favourable changes in biomarkers of inflammation, coagulation and endothelial dysfunction [16, 18]. Metformin had a triacylglycerol-lowering effect of smaller magnitude and produced more modest changes in novel biomarkers $[16,18]$. The cumulative incidence of the metabolic syndrome was reduced $41 \%$ by the lifestyle and $17 \%$ by the metformin intervention in the DPP [21] and by $38 \%$ in the FDPS lifestyle intervention group [35]. However, in the DPPOS, by a median of 10 years of total follow-up, in parallel with increasing use of antihypertensive and lipid-lowering medications, there were significant decreases from baseline in systolic and diastolic BP $(\sim 2-$ $3 \mathrm{mmHg}$ and 5-6 mmHg, respectively), LDL-cholesterol levels (0.47-0.54 mmol/l) and triacylglycerols $(0.18-0.32 \mathrm{mmol} / \mathrm{l})$ across all three treatment groups, with no significant differences among them [16]. The use of antihypertensive and lipid-lowering agents was significantly lower in the lifestyle intervention group compared with the original placebo- and metforminassigned groups over time. Importantly, development of diabetes was accompanied by unfavourable changes in cardiometabolic factors in all three DPP intervention arms [19, 20]. In sum, while both lifestyle and pharmacological interventions produce favourable changes in CVD risk factors, the question of whether diabetes prevention per se reduces the CVD risk profile is likely to remain difficult to answer because of confounding by the effects of the interventions themselves and the progressive use over time of antihypertensive and lipid lowering medications, especially in those who develop diabetes.

\section{Discussion}

The available studies that assess the role of diabetes prevention on diabetes-associated vascular complications do not provide consistent support of a benefit. Some studies support a beneficial effect on microvascular complications [9, 14, 29], though even these are not internally consistent. In the DQDPOS, a statistically significant effect of lifestyle intervention was limited to severe retinopathy; point estimates of effects on neuropathy or nephropathy were of the same magnitude but with wider confidence intervals [12]. The DPPOS showed that the interventions had no effect compared with placebo on the aggregate microvascular outcomes, though again there are inconsistencies in that lifestyle modification reduced their prevalence in women but not men [14]. Similarly, some clinical trials have demonstrated a benefit with regard to cardiovascular risk factors [16, 18-21], CIMT progression [31], CVD events [10, 12, 24, 25] and total mortality [10-12], while others have failed to provide support 
[26]. Despite the fact that type 2 diabetes is defined by a level of hyperglycaemia that is associated with complications, current results are neither consistent nor compelling in demonstrating that diabetes prevention leads to reduced complications. What might explain this paradox?

A number of major factors probably underlie these weak and inconsistent associations. First, the development of diabetic microvascular complications is thought to occur many years after the onset of hyperglycaemia-defined diabetes and most of the trials have been relatively brief in duration. The brief duration is of special concern since the vascular outcomes in many of the studies have included advanced stages (e.g. laser photocoagulation and vitrectomy for retinopathy, reduced eGFR for nephropathy and major atherosclerotic events for CVD). In the two trials with longest follow-up, DQDPOS and DPPOS, there is some, albeit inconsistent, evidence of benefit. The DQDPOS finding of a significant effect for lifestyle intervention on severe retinopathy, but not nephropathy or neuropathy, is presumably due to the lower number of instances of the latter resulting in wider confidence intervals, because the point estimates for rate reduction are nearly the same for all three complications [12]. The difference by sex in DPPOS, with a potential lifestyle benefit in women only, is surprising [14]. This may reflect the inclusion of women with previous gestational diabetes, a 'metabolic stress' obviously limited to women in the DPP. Major sex differences in the effect of interventions have been seen with other DPP outcomes (e.g. in the prevention of the metabolic syndrome [21]).

Important factors likely related to the weak effect of preventing diabetes on complication risk in the DPPOS are the low absolute $\mathrm{HbA}_{1 \mathrm{c}}$ levels (Table 1, Fig. 1) and modest separation in those levels between the participants who developed diabetes and those who did not. Although the limited separation in chronic hyperglycaemia and relatively brief duration of follow-up (i.e. exposure to hyperglycaemia) likely explain much of the weak effect, other mechanisms deserve consideration.

One possibility is that the hyperglycaemia associated with diabetes might not be the major pathogenetic pathway to complications. This is unlikely, given the overwhelming and consistent evidence from earlier type 1 and type 2 diabetes trials, such as the DCCT [37] and UKPDS [38], demonstrating the strong causal role of hyperglycaemia in microvascular complications and its less powerful role in CVD [38, 39]. Another possible explanation is that the 'complications of diabetes' may not be specific to diabetes or to diabetes as currently defined by glycaemic levels. The relatively diabetes-specific complication retinopathy is present during the prediabetes state, as shown in the Pima Indian epidemiology study [40], the Da Qing IGT and Diabetes Study [41] and the DPP [42]. The occurrence of diabetes-specific complications, such as retinopathy, and less-diabetes-specific complications, such as albuminuria and peripheral neuropathy, in the prediabetic or non-diabetic population may interfere with our ability to detect a difference in the development of such complications between those individuals who develop diabetes and those who do not. In addition, early occurrence of complications may reflect a stronger genetic susceptibility [43-45] and this might reduce the power to detect an effect of diabetes prevention in the limited follow-up of trials to date.

Finally, what are the implications of the current weak and incomplete data relating reduced diabetes development to reduced complication risk? First, extended follow-up of current trials will be critical to resolving the uncertainty. Second, data are sufficiently encouraging not to undermine the general case for diabetes prevention, which can be justified on other grounds. However, the lengthy time likely needed to demonstrate prevention of complications should be carefully considered in cost-effectiveness analyses. Third, these findings add further strength to the argument that we should also emphasise research focusing on non-glycaemic pathways for the development of complications, particularly for CVD prevention where there are many interventions that could be applied in parallel with diabetes prevention.

Acknowledgements The Research Group gratefully acknowledges the commitment and dedication of the participants of the DPP and DPPOS. A complete list of centres, investigators and staff can be found in the electronic supplementary material (ESM).

Funding During the DPP and DPPOS, the National Institute of Diabetes and Digestive and Kidney Diseases (NIDDK) of the National Institutes of Health provided funding to the clinical centres and the Coordinating Center for the design and conduct of the study and collection, management, analysis and interpretation of the data (U01 DK048489). The Southwestern American Indian Centers were supported directly by the NIDDK, including its Intramural Research Program, and the Indian Health Service. The General Clinical Research Center Program, National Center for Research Resources and the Department of Veterans Affairs supported data collection at many of the clinical centres. Funding was also provided by the National Institute of Child Health and Human Development, the National Institute on Aging, the National Eye Institute, the National Heart Lung and Blood Institute, the National Cancer Institute, the Office of Research on Women's Health, the National Institute on Minority Health and Health Disparities, the Centers for Disease Control and Prevention and the American Diabetes Association. Bristol-Myers Squibb and Parke-Davis provided additional funding and material support during the DPP. Lipha (Merck-Sante) provided medication and LifeScan Inc. donated materials during the DPP and DPPOS. This research was also supported, in part, by the intramural research program of the NIDDK. LifeScan Inc., Health O Meter, Hoechst Marion Roussel, Inc., Merck-Medco Managed Care, Inc., Merck and Co., Nike Sports Marketing, Slim Fast Foods Co. and Quaker Oats Co. donated materials, equipment or medicines for concomitant conditions. McKesson BioServices Corp., Matthews Media Group, Inc. and the Henry M. Jackson Foundation provided support services under subcontract with the Coordinating Centre. The sponsor of this study was represented on the Steering Committee and played a part in study design, how the study was done and publication. The funding agency was not represented on the writing group, although all members of the Steering Committee had input into the report's contents. The opinions expressed are those of the investigators and do not necessarily reflect the views of the funding agencies.

Duality of interest The authors declare that there is no duality of interest associated with this manuscript. 
Contribution statement DMN drafted the original paper with assistance from all of the authors. All authors revised the paper critically for important intellectual content. All authors approved the version to be published.

\section{References}

1. The Expert Committee on the Diagnosis and Classification of Diabetes Mellitus (1997) Report of the Expert Committee on the Diagnosis and Classification of Diabetes Mellitus. Diabetes Care 20(7):1183-1197. https://doi.org/10.2337/diacare.20.7.1183

2. International Expert Committee (2009) International Expert Committee report on the role of the A1C assay in the diagnosis of diabetes. Diabetes Care 32(7):1327-1334. https://doi.org/10.2337/ dc09-9033

3. Rosenquist KJ, Fox CS Mortality trends in type 2 diabetes. In: Cowie CC, Casagrande SS, Menke A et al (eds) Diabetes in America, 3rd edn. National Institutes of Health, Bethesda, pp 36.1-36.14

4. American Diabetes Association (2018) Economic costs of diabetes in the US in 2017. Diabetes Care 41(5):917-928. https://doi.org/10. 2337/dci18-0007

5. Crandall JP, Knowler WC, Kahn SE et al (2008) The prevention of type 2 diabetes. Nat Clin Pract Endocrinol Metab 4(7):382-393. https://doi.org/10.1038/ncpendmet0843

6. Knowler WC, Crandall JP, Chiasson J-L, Nathan DM Prevention of diabetes. In: Cowie CC, Casagrande SS, Menke A et al (eds) Diabetes in America, 3rd edn. National Institutes of Health, Bethesda, pp 38.1-38.21

7. Pan XR, Li GW, Hu YH et al (1997) Effects of diet and exercise in preventing NIDDM in people with impaired glucose tolerance. The Da Qing IGT and Diabetes Study. Diabetes Care 20(4):537-544. https://doi.org/10.2337/diacare.20.4.537

8. Li G, Zhang P, Wang J et al (2008) The long-term effect of lifestyle interventions to prevent diabetes in the Da Qing Diabetes Prevention Study: a 20-year follow-up study. Lancet 371(9626): 1783-1789. https://doi.org/10.1016/S0140-6736(08)60766-7

9. Gong Q, Gregg EW, Wang J et al (2011) Long-term effects of a randomized trial of a 6-year lifestyle intervention in impaired glucose tolerance on diabetes-related microvascular complications: the China Da Qing Diabetes Prevention Outcome Study. Diabetologia 54(2):300-307. https://doi.org/10.1007/s00125-010-1948-9

10. Li G, Zhang P, Wang J et al (2014) Cardiovascular mortality, all cause mortality and diabetes incidence after lifestyle intervention for people with impaired glucose tolerance in the Da Qing Diabetes Prevention Study: a 23-year follow-up study. Lancet Diabetes Endocrinol 2(6):474-480. https://doi.org/10.1016/S2213-8587(14) 70057-9

11. Gong Q, Zhang P, Wang J et al (2016) Changes in mortality in people with IGT before and after the onset of diabetes during the 23-year follow-up of the Da Qing Diabetes Prevention Study. Diabetes Care 39(9):1550-1555. https://doi.org/10.2337/dc160429

12. Gong Q, Zhang P, Ma J et al (2019) Morbidity and mortality after lifestyle intervention for people with impaired glucose tolerance: 30-year results of the Da Qing Diabetes Prevention Outcome Study. Lancet Diabetes Endocrinol 7(6):452-461. https://doi.org/ 10.1016/S2213-8587(19)30093-2

13. Diabetes Prevention Program Research Group (2002) Reduction in the incidence of type 2 diabetes with lifestyle intervention or metformin. N Engl J Med 346:393-403
14. Diabetes Prevention Program Research Group (2015) Long-term effects of lifestyle intervention or metformin on diabetes development and microvascular complications over 15-year follow-up: the Diabetes Prevention Program Outcome Study. Lancet Diabetes Endocrinol 3:866-875

15. Perreault L, Pan Q, Aroda VR et al (2017) Exploring residual risk for diabetes and microvascular disease in the Diabetes Prevention Program Outcome Study. Diabet Med 34(12):1747-1755. https:// doi.org/10.1111/dme.13453

16. Diabetes Prevention Program Outcomes Study Research Group (2013) Long-term effects of the Diabetes Prevention Program interventions on cardiovascular risk factors: a report from the DPP Outcomes Study. Diabet Med 30:46-55

17. Goldberg RB, Aroda VR, Bluemke DA et al (2017) Effect of longterm metformin and lifestyle in the Diabetes Prevention Program and its Outcome Study on coronary artery calcium. Circulation. 136(1):52-64. https://doi.org/10.1161/CIRCULATIONAHA.116. 025483

18. Goldberg RB, Bray GA, Marcovina SM et al (2019) Nontraditional biomarkers and incident diabetes in the Diabetes Prevention Program: comparative effects of lifestyle and metformin interventions. Diabetologia 62(1):58-69. https://doi.org/10.1007/ s00125-018-4748-2

19. Goldberg RB, Temprosa M, Haffner S et al (2009) Effect of progression from impaired glucose tolerance to diabetes on cardiovascular risk factors and its amelioration by lifestyle and metformin intervention: the Diabetes Prevention Program randomized trial by the Diabetes Prevention Program Research Group. Diabetes Care 32(4):726-732. https://doi.org/10.2337/dc08-0494

20. Goldberg RB, Temprosa MG, Mather KJ et al (2014) Lifestyle and metformin interventions have a durable effect to lower CRP and tPA levels in the diabetes prevention program except in those who develop diabetes. Diabetes Care 37(8):2253-2260. https://doi.org/ $10.2337 / \mathrm{dc} 13-2471$

21. Orchard TJ, Temprosa M, Goldberg R et al (2005) The effect of metformin and intensive lifestyle intervention on the metabolic syndrome: the Diabetes Prevention Program randomized trial. Ann Intern Med 142(8):611-619. https://doi.org/10.7326/0003-4819142-8-200504190-00009

22. NAVIGATOR Study Group (2010) Effect of nateglinide on the incidence of diabetes and cardiovascular events. N Engl J Med 362:1463-1476

23. NAVIGATOR Study Group (2010) Effect of valsartan on the incidence of diabetes and cardiovascular events. N Engl J Med 362: $1477-1490$

24. Chiasson J-L, Josse RG, Ramon Gomis R, Hanefeld M, Karasik A, Laakso M (2002) Acarbose for prevention of type 2 diabetes mellitus: the STOPNIDDM randomised trial. Lancet 359(9323): 2072-2077. https://doi.org/10.1016/S0140-6736(02)08905-5

25. Chiasson JL, Josse RG, Gomis R et al (2003) Acarbose treatment and the risk of cardiovascular disease and hypertension in patients with impaired glucose tolerance. The STOP-NIDDM trial. JAMA 290(4):486-494. https://doi.org/10.1001/jama.290.4.486

26. Holman RR, Coleman RL, Chan JCN et al (2017) Effects of acarbose on cardiovascular and diabetes outcomes in patients with coronary heart disease and impaired glucose tolerance (ACE): a randomised, double-blind, placebo controlled trial. Lancet Diabetes Endocrinol 5(11):877-886. https://doi.org/10.1016/ S2213-8587(17)30309-1

27. DREAM Trial Investigators (2006) Effect of ramipril on the incidence of diabetes. N Engl J Med 355:1551-1562

28. DREAM Trial Investigators (2006) Effect of rosiglitazone on the frequency of diabetes in patients with impaired glucose tolerance or impaired fasting glucose: a randomized controlled trial. Lancet 358: 1096-1105 
29. Dagenais GR, Gerstein HC, Holman R et al (2008) Effects of ramipril and rosiglitazone on cardiovascular and renal outcomes in people with impaired glucose tolerance or impaired fasting glucose: results of the Diabetes Reduction Assessment with Ramipril and Rosiglitazone Medication (DREAM) trial. Diabetes Care 31(5):1007-1014. https://doi.org/10.2337/dc07-1868

30. DeFronzo RA, Tripathy D, Schewnke DC et al (2011) Pioglitazone for diabetes prevention in impaired glucose tolerance. N Engl J Med 364(12):1104-1115. https://doi.org/10.1056/NEJMoa1010949

31. Saremi A, Schwenke DC, Buchanan TA et al (2013) Pioglitazone slows progression of atherosclerosis in prediabetes independent of changes in cardiovascular risk factors. Arterioscler Thromb Vasc Biol 33(2):393-399. https://doi.org/10.1161/ATVBAHA.112. 300346

32. ORIGIN Trial Investigators, Gerstein HC, Bosch J et al (2012) Basal insulin and cardiovascular and other outcomes in dysglycemia. N Engl J Med 367(4):319-328. https://doi.org/10. 1056/NEJMoa1203858

33. ORIGIN Trial Investigators (2014) Basal insulin glargine and microvascular outcomes in dysglycemic individuals: results of the Outcome Reduction with an initial Glargine Intervention (ORIGIN) trial. Diabetologia 57:1325-1331

34. Uusitupa M, Peltonen M, Lindström J et al (2009) Ten-year mortality and cardiovascular morbidity in the Finnish Diabetes Prevention Study-secondary analysis of the randomized trial. PLoS One 4(5):e5656. https://doi.org/10.1371/journal.pone. 0005656

35. Ilanne-Parikka P, Eriksson JG, Lindström J et al (2008) Effect of lifestyle intervention on the occurrence of metabolic syndrome and its components in the Finnish Diabetes Prevention Study. Diabetes Care 31(4):805-807. https://doi.org/10.2337/dc07-1117

36. Lonn EM, Gerstein HC, Sheridan P et al (2009) Effect of ramipril and of rosiglitazone on carotid intima-media thickness in people with impaired glucose tolerance or impaired fasting glucose: STARR (Study of Atherosclerosis with Ramipril and Rosiglitazone). J Am Coll Cardiol 53(22):2028-2035. https://doi. org/10.1016/j.jacc.2008.12.072

37. Lachin JM, Genuth S, Nathan DM, Zinman B, Rutledge BN (2008) Effect of glycemic exposure on the risk of microvascular complications in the Diabetes Control and Complications Trial: revisited. Diabetes 57(4):995-1001. https://doi.org/10.2337/db07-1618

38. Stratton IM, Adler AI, Neil HA et al (2000) Association of glycaemia with macrovascular and microvascular complications of type 2 diabetes (UKPDS 35). BMJ 321(7258):405-412. https://doi.org/10.1136/bmj.321.7258.405

39. DCCT/EDIC Research Group (2016) Risk factors for cardiovascular disease in type 1 diabetes. Diabetes 65:1370-1379

40. Nagi DK, Pettitt DJ, Bennett PH, Klein R, Knowler WC (1997) Diabetic retinopathy assessed by fundus photography in Pima Indians with impaired glucose tolerance and non-insulindependent diabetes mellitus. Diabet Med 14(6):449-456. https:// doi.org/10.1002/(SICI)1096-9136(199706)14:6<449::AIDDIA367>3.0.CO;2-D

41. Hu YH, Pan XR, Liu PA, Li GW, Howard BV, Bennett PH (1991) Coronary heart disease and diabetic retinopathy in newly diagnosed diabetes in Da Qing, China: the Da Qing IGT and Diabetes Study. Acta Diabetol 28(2):169-173. https://doi.org/10.1007/ BF00579721

42. Diabetes Prevention Program Research Group (2007) The prevalence of retinopathy in impaired glucose tolerance and recent-onset diabetes in the Diabetes Prevention Program. Diabet Med 24(2): 137-144. https://doi.org/10.1111/j.1464-5491.2007.02043.x

43. Orchard TJ, Chang YF, Ferrell RE, Petro N, Ellis DE (2002) Nephropathy in type 1 diabetes: a manifestation of insulin resistance and multiple genetic susceptibilities? Further evidence from the Pittsburgh Epidemiology Complication Study. Kidney Int 62(3):963-970. https://doi.org/10.1046/j.1523-1755.2002.00507.x

44. Orchard TJ, Sun W, Cleary PA et al (2013) Haptoglobin genotype and the rate of renal function decline in the Diabetes Control and Complications Trial/Epidemiology of Diabetes Interventions and Complications study. Diabetes 62(9):3218-3223. https://doi.org/ $10.2337 / \mathrm{db} 13-0256$

45. van Zuydam NR, Ahlqvist E, Sandholm N et al (2018) A genome wide association study of diabetic kidney disease in subjects with type 2 diabetes. Diabetes. 67(7):1414-1427. https://doi.org/10. 2337/db17-0914

Publisher's note Springer Nature remains neutral with regard to jurisdictional claims in published maps and institutional affiliations. 